\title{
Riverine Complexity: Islandness, socio-spatial perceptions and modification-a case study of the lower Richmond River (Eastern Australia)
}

\author{
Christian Fleury \\ University of Caen Normandy, France \\ fleury.cote@wanadoo.fr
}

\author{
Philip Hayward \\ University of Technology Sydney, Australia \\ prhshima@gmail.com (corresponding author)
}

\begin{abstract}
In its initial incarnation, island studies regarded islands as highly distinct entities that justified a relatively closed discipline. This orientation was first widened by address to issues such as the linkage of (pre-existent) islands to adjacent areas and, over the last decade, has been further modified by consideration of island-like areas. The latter has led to an increasing acknowledgement that, in some contexts, at least, islands form components of complex aquatic and terrestrial systems in which islandness is a less distinctive attribute than in the case of archetypal (usually marine) islands. While neglected by island studies, river systems that include islands, peninsulas and/or engineered waterfront developments are significant for problematising the distinctiveness of islands and thereby merit attention. This article sets out to map some of the complexities around islands and rivers with specific regard to the Richmond River in northern New South Wales, Australia. We profile this river since its lower reaches feature a range of natural and artificial island and island-like features, including the engineered area known as Ballina Island. We develop our study with regard to both Indigenous perceptions of the riverine space and disruptions, interventions and innovations resulting from European settlement in the region. As such, the article attempts to progress island studies' research on riverine environments, to problematise the notion of discrete islands/islandness in such contexts and to prompt greater disciplinary reflection on the issues arising from such scrutiny.
\end{abstract}

Keywords: artificial islands, Ballina, Cabbage Tree Island, canalisation, Richmond River, rivers, riverine environments, river islands

https://doi.org/10.24043/isj.141 • Received August 2020, Early access December 2020

(C) Island Studies Journal, 2021 


\section{Introduction}

Along with its core concern with archetypal islands entirely surrounded by water, island studies has expanded in recent years to address a fringe of more transitional locales. The first notable example of the latter was the examination of the effects of creating fixed links on islands offered by contributors to Baldacchino's (2007) Bridging Islands. The volume examined the extent to which fixed links could be understood to have 'de-islanded' islands and the various responses of islanders to linkage to mainlands or other islands in terms of their everyday life and/or the identity of their communities. While the individual studies in the volume were admirably objective in their evaluations and reflections, it is not insignificant, in terms of the volume's topic, that many early contributors to island studies were islophiles who had varying degrees of idealisation and/or romanticisation of islands. For such sensibilities, de-islanding was (and still appears to be) a particularly and sensitive topic.

These islophilic tendencies were alluded to by Grydehøj $(2017$, p. 3) in his call for contemporary island studies "to grapple with a number of problematic tendencies within the field and the wider scholarship, including by challenging the misuse of island spatiality to produce idealised visions of islands." As a number of journal editors and referees can bear witness, the latter tendency is still present in the field, with a small but significant number of researchers retaining residual adherence to concepts of "essential islandness" and/or of islands as being innately 'romantic,' 'mysterious,' 'inspiring' etc. While not characterising the contributors to Baldacchino's anthology as manifesting such perceptions, it could also be asserted that an underlying theme of Baldacchino's anthology is that islands manifest as appealing natural physical phenomena whereas linkage/de-islanding is a problematic result of human engineering (suggesting an opposition of the organic and inorganic).

It is notable, in the above regard, that the reverse phenomenon of islands created by human engineering has received less attention in island studies. This has particularly been the case with regard to islands incidentally created through the construction of water transit routes or drainage channels. The islandness of such incidentally configured locales has rarely been the cause of comment or analysis in part, perhaps, due to a significant number of such locations being somewhat ephemeral. Many such islands were created during the $18^{\text {th }}$ and $19^{\text {th }}$ Centuries and were often promptly de-islanded as a result of the construction of fixed links across the (usually) narrow waterways concerned to service emerging road and rail systems. As the discussion of Ballina Island in this article illustrates, such islands predominantly exist in a cartographic sense, in that they can be discerned through observation of their representation. When connected by low road, rail or pedestrian bridges that allow seamless access across canals, there is often little to suggest the islandness of one or other side of the waterway. If such perceptions of canalised islandness are evident in the early $21^{\text {st }}$ Century, it is often with regard to retained nomenclature rather than strong local or external assertions of island identity.

The creation of other types of engineered islands has also received limited attention in island studies. One possible explanation of this is provided by the English language term most often used to refer to them, i.e. artificial. In its broadest sense the term refers to something that is the product of the artifice of human ingenuity and/or expediency and thereby indicates such products as being unnatural or inorganic. Used pejoratively, it suggests the product of artifice to be less compelling, complete and/or effective than the natural, 'real' thing-i.e. of it being ersatz (innately inferior in substance, essence and affect to a referent commodity). 
Arguably swayed by the lingering isolophilia apparent in island studies, artificial islands appear to hold less appeal to researchers than organic ones. If anything, the case of Venice exemplifies the marginality of artificial islands referred to above. Throughout its analysis in a range of research disciplines and cultural practices, it has been the artifice of the city and its cultural heritage that has been central to discussion. With the exception of Casagrande's (2016) study on the management of Venetian heritage resources published in Urban Island Studies (UIS) and Grydehøj and Casagrande's (2020) article on archipelagic relationality and transport structure in its lagoon published in the geography publication Area, the city has been largely overlooked by island studies scholars.

The principal exception to the above tendency was provided by Gupta (2015), who addressed Dubai's World Islands project (which commenced in 2003 and is still incomplete). Actively engaging with many of the romanticist/essentialist discourses referred to above, she contended (in the pre-COVID 19 era) that lavish artificial island projects exemplified the "post-modern neoliberal world of tourism [...] and liquidity [...] where travel, lightness, and fluidity are the major metaphors of our time, and where certain islands are no longer materially 'real' geological formations that have simply been found in nature" but are, instead "artificially designed" involving "technological mediations on a massive scale" (Gupta, 2015, p. 182). While the "lightness" and "fluidity" of tourism and international capital are markedly different in the current pandemic period, her latter characterisations are also pertinent for the islets China has constructed in the South China Sea over the last decade, a phenomenon that island studies has also been slow to engage with despite academics from various other fields having shown an interest in the phenomenon since the early 2010s (see, for instance, Hideshi, 2013).

In terms of discussion of less spectacular locations, contributors to the journal Urban Island Studies have explored the creation of artificial islands as part of more multi-facetted expansions of island cities through land 'reclamation' (Grydehøj, 2015) and as components of integrated 'finger island' canal estate (FICE) developments in various locales, such as Australia's Gold Coast (Hayward \& Fleury, 2016). In the latter article, in particular, we were less concerned with orthodox island studies approaches and more in tune with the "expanded" vision for the discipline offered by Hayward (2016). The "expanded" approach includes address to the perspectives introduced by Fleury and Raoulx (2016) and explored by Anderson (2016), Gold (2016), and Potiki (2016) with regard to the manner in which certain peninsular areas can be considered as 'almost-islands,' possessing many attributes of islands without being islands.

As we discuss, FICEs are complex spaces that cannot be easily characterised in terms of individual component islands, linked islands, almost-islands and/or peninsulas but are, rather, integrated assemblages that manifest (and blur) aspects of all four categories (Hayward \& Fleury, 2016). While not as spectacular as Dubai's World Islands development, the Gold Coast's FICEs (like similar developments in Florida) are notable for both their scale and aggregation, often dominating large areas of the city. But along with such metadevelopments, land reclamation, canalisation and FICE developments also occur in smaller and less spectacular spaces where they act as components of lived environments that embody aspects of islandness, almost-islandness and peninsularity in various ways. Acknowledgement of this point brings us to another lacuna in island studies, the consideration of river islands and their relationships to river systems and the shores that enclose them. 
While Lahir-Dutt and Gopa (2013) have provided a detailed study of riverbed islands in lower Bengal, only a handful of articles on river islands have appeared in dedicated island studies journals and anthologies to date (e.g. Lahari-Dutt, 2014; Baruah \& Mukherkee, 2018; Hong, 2020). Of these, the latter is of particular relevance to our study by developing an analysis of particular riverine conditions and phenomena with regard to three Chinese islands: Chongmin, Baguazhou and Dongzhou. In the introduction to his article Hong contends that:

Many cultural imaginations and representations of islands have been undertaken with regard to images of saltwater rather than freshwater islands [...] Hay (2013) attributes this to the perception that freshwater islands, in general, including river islands, are often too integrated within urban surroundings to exhibit significant aspects of (what Island Studies conceives of as) islandness. Another reason may be that due to their proximity to non-island environments, it is difficult to find island-specific cultures or species on them. Within Island Studies' commitment to studying islands on their own terms, river islands in general may suggest themselves as being less island-like than their maritime counterparts, though few would have difficulty still conceptualising them as islands. (Hong, 2020, p. 88)

Zhang and Grydehøj (2020) provide a useful counterpoint to Hong's discussion in their study of the Zhousan archipelago, located at the interface of the Yangtze River and its delta, in which they draw on islanders' own perceptions of place:

Like many other island territories, the real and significant economic, industrial and transport functions that Zhoushan provides for its mainland hinterlands are conceptually dominated by a number of island stereotypes linked to remoteness, isolation and otherworldliness. Islanders, (Zhoushan residents) though, see their archipelago as urban, even if it does not match city-oriented conceptions of urbanism [and] recognise tensions between Zhoushan's island conditioned integration into a massive urban agglomeration and their ideas regarding what they feel islands ought to be like - the tension between openness and closure, complexity and simplicity, relation and nonrelation that has been so central to discussions within relational and urban island studies.

Our readings of the lower Richmond River also draw on recent work on the manner in which the human engineering of waterways for transport, drainage and irrigation has created "unique cultural landscapes" that have "coalesced to create social identities" (Timothy, 2018, p. xviii), producing a "fluvial sense of space" amongst the communities that inhabit them (Vallerani, 2018, p. 2). As Visentin (2018, pp. 252-253) identifies, historical studies of the creation of such spaces can allow us to understand "how past heritage and landscape waterways interact with the present" with particular regard to the "life cycle model" of canalised landscapes as they transition from industrial functionalism to leisure and recreational uses. Within this nexus - and as part of a larger research project on the so-called 'Northern Rivers' region of Far North New South Wales conducted by Southern Cross University's LabX initiative-we examine specific human interventions in riverine landscapes and related infrastructure. As Larkin (2013) has identified, infra-structures are a 
vital, if often overlooked aspect of socio-anthropological studies: as networks, that facilitate flows of people, commodities and related commercial enterprises and as the material-logistical architecture that enables and generates the networks, "providing the undergirding of modern societies, and... the ambient environment of everyday life" (Larkin, 2013, p. 327).

In what follows, we analyse the related socio-economic and socio-cultural operationality of two locations in the Richmond River, Cabbage Tree Island and Ballina, perceptions of a larger entity we term 'East Bank Area' (EBA) and the nature of the unnamed almost-island created by fluvial deposition at Swan Bay. We approach Cabbage Tree Island as a preconstituted locale that a population has relocated to and inhabited in a manner that has socio-culturally islanded the resultant community. By contrast, we characterise Ballina as a complex, human engineered estuarine space with nomenclative designation as an island. The third locale we briefly characterise and discuss as an island (EBA) has a negligible presence in the consciousness of regional inhabitants and is one that primarily appears as such when the lower reaches of the Richmond River are viewed through the lens of island studies. The fourth, location, Swan Bay, is discussed as an almost-island linked to the shore by natural processes, rather by than the construction of fixed links (as in the case of Ballina Island). Taking a historical perspective on the interaction of various facets of these locales, we identify them as complex and dynamic spaces with components that can be considered islanded and/or islandish in various ways. Similarly, we identify the discrete but associated infrastructural factors that create these shifting entities and contextualise them within a riverine space in which islandness and non-islandness are less significant than an overall integration within marine and terrestrial transit routes.

\section{The Richmond River, its locale and Indigenous cultural history}

Note: In the following discussion we use the term 'nation' to refer to Indigenous communities with a shared language inhabiting a contiguous space and the term 'clan' to refer to sub-groups within such nations that are normally characterised by their area of inhabitation and their particular beliefs, practices and dialect. But within this schema it should be acknowledged that such clans and, to some extent, nations, had patterns of seasonal and other occasional mobilities that brought them into contact with other communities with which they had various types of reciprocal and/or conflictual relationships. Given the complexity concerning place-naming in Indigenous Australian discourse (referred to below) we use English language settler names for locations (such as the Richmond River) even when referring to these during the pre-colonial period when these names were (necessarily) not in use.

The Richmond River is $237 \mathrm{~km}$ in length and rises at $256 \mathrm{~m}$ to the west of Mount Lindesay in the McPherson Ranges. As Figure 1 indicates, the river initially runs south-east until it is joined by various tributaries and enters its estuarine phase just south of Coraki, where it loops north east to enter the sea at Ballina. The river's catchment area is around $6,860 \mathrm{~km}^{2}$ and falls largely within the territory of the Indigenous Bundjalung nation. Approximately $15 \%$ of the Richmond River catchment area comprises floodplains adjacent to the river that continue to be regularly inundated and there are also a number of wetlands, including the extensive Tuckean Swamp, west of Wardell (Kijas, 2009). The river includes a number of eyots (small islands caused by the deposits of sediment in lower reaches of rivers that are usually approximately parallel to the shore) named Cabbage Tree, Pelican, Goat, 
Little Pimlico and Pimlico islands (the latter four being uninhabited). The lower reaches of the river offer a rich range of food sources (including waterbirds, fish, crustaceans and shellfish) that sustained local clans in the pre-colonial period. Evidence of significant consumption of shellfish by the Bundjalung community can be found in the form of middens around Ballina's North Creek.

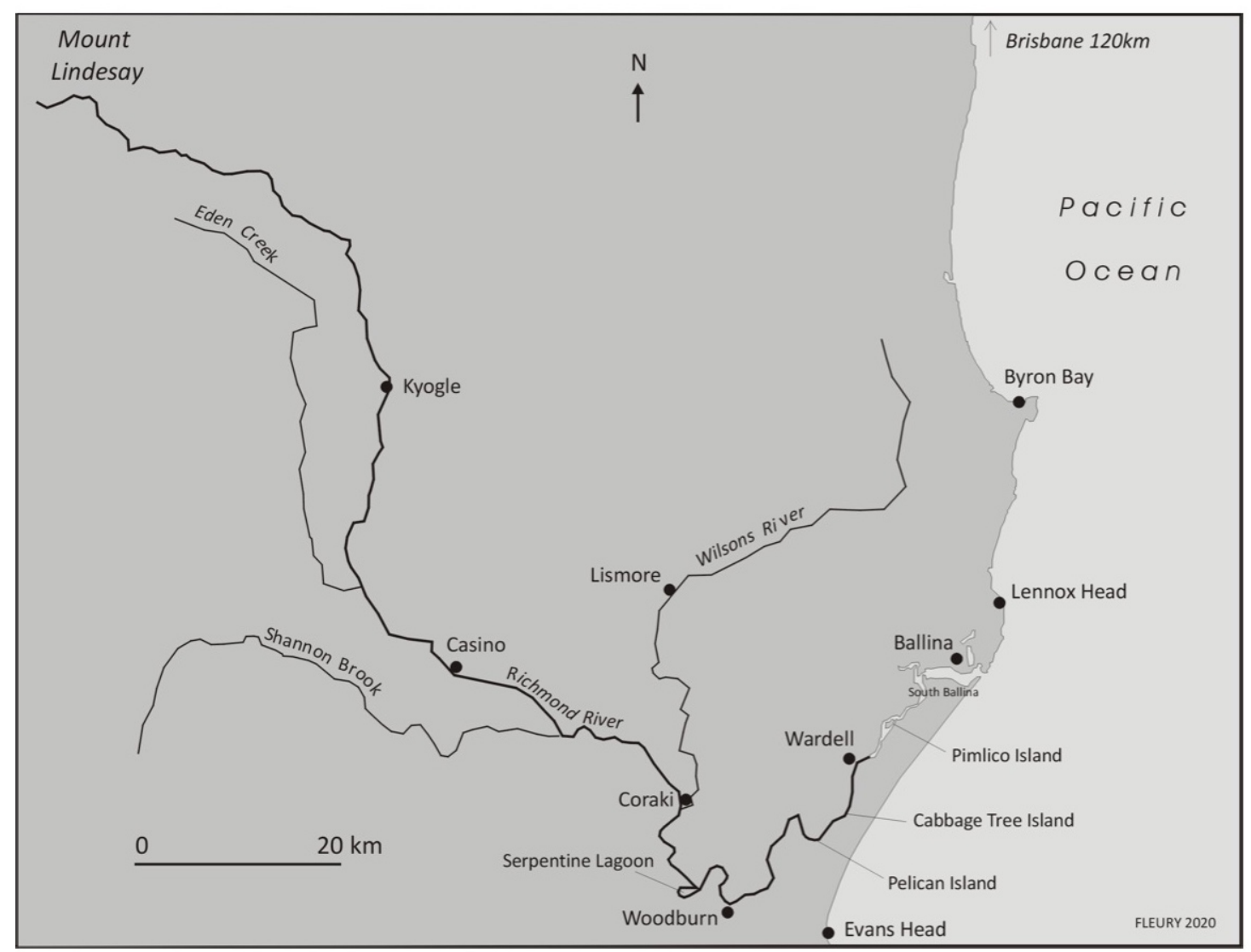

Figure 1: The Richmond River catchment area, its main tributaries and key contemporary locations. (C) Christian Fleury, 2020

In its passage from the McPherson Ranges, the Richmond River flows through various Bundjalung clan lands that had distinct dialects, sets of terms and mythologies (Sharpe, 1985) in the precolonial period. The Bundjalung-Yugambeh Dictionary (2020) lists a number of terms that indicate bodies of water of various types. These include the term balun, used broadly across the nation to refer to rivers and smaller creeks (and, cross-associatively to refer to the astronomical formation known in western cultures as the Milky Way), and more localised terms such as nyuring (used by clans around the lower Richmond River and, thereby, perhaps, denoting the broad, tidal nature of the river at that point). Within this context it is unclear to what extent individual clans conceptualised the Richmond as a singular (coherent, distinct) river system that flowed through their nation's territory (in the manner a western geographical/cartographic consciousness might) and/or as a flowing water space that crossed particular communities' lands and transitioned to adjacent and more distant communities. Similarly, it is unclear whether communities near the sea had senses of the river's origins in a trickle in a mountainous area far inland. Ryan (1963, pp. 40-43) also notes a large number of 
terms for spots on rivers known as good places to catch specific types of fish and of swampy areas home to plants of particular utility.

Of particular relevance to this article, there is no evidence that the Bundjalung community shared a general concept of islands/islandness, in the western manner exemplified by island studies, in that their language lacks any standard term for such a formation in any glossary produced to date. Correspondingly, Indigenous place names often give no indication of generalist categories, particularly with regard to standard nouns and concepts such as islands, rivers (etc.) used in western language in combination with a specific name to indicate a specific location (e.g. Canvey Island, River Thames etc.) Further complicating matters, throughout Australia, Indigenous place naming often combined references to specific landscapes and/or particular events with cosmological associations, freely mixing the two. This mirrored the association of animate entities with spiritual ones (themselves considered as animate, albeit in different ways) in Indigenous culture. Some insight into this can be gleaned from the complexity attributed to the term wardjam in Bundjalung culture. Across the nation it could be used to refer to fish, sharks or whales and/or, cross-associatively, with aquatic human-like spirits and other mythic creatures (or, indeed, with folkloric monsters more generally) (Bundjalung-Yugambeh Dictionary, 2020).

The cosmology, livelihood practices and sustainability of local Indigenous societies were severely impact by the arrival of British timber extractors, settlers, pastoralists and traders from the 1840 s on. A variety of genocidal practices, including massacres, seizures of land, communication of infectious diseases, harassment, confinement in particular areas and a range other discriminatory and iniquitous practices depleted the Bundjalung population and marginalised them in their own national territory. The very different worldviews, livelihood practices, forms of transport and geo-spatial perceptions of European migrants superimposed themselves over the prior culture of the region and resulted in new uses and names of landscape features.

While some Indigenous place names have persisted, albeit in slightly modified form, such as Coraki (derived from gurigay, a term of unknown meaning associated with the area), many modern English language names for locations around the Richmond River follow standard western practice and either use western words for plants and animals observed in the areas concerned (such as the aforementioned islands named after cabbage trees, goats and pelicans) or with regard to particular European associations, such as Pimlico and Little Pimlico islands. In addition to place naming, settler practices also affected Indigenous people's experiences of place and, in some circumstances, lead to some communities' social identifications as islanders as a result of social islanding in singular locations, Cabbage Tree Island and its community being a case in point.

\section{Cabbage Tree Island}

Cabbage Tree Island's establishment as an Aboriginal settlement resulted from and is emblematic of a pattern of conflict across the broader region of the mid- and lowerRichmond River. As the Ballina Shire Council's (2004, p. 29) 'Wardell Community Based Heritage Study' has identified (referring to Indigenous Australians as Kooris):

resisted both the invasion of their territory and the violence of Europeans by responding in a number of ways. Aside from adopting traditional warfare resistance, 
and instead of retreating and 'dying out' as European scientific theory suggested would happen, many Kooris sought to establish new ways to survive in the new environment of European capitalism. Employment with Europeans for money or for rations enabled Kooris to supplement diminished native food sources, as well as develop European farming skills.

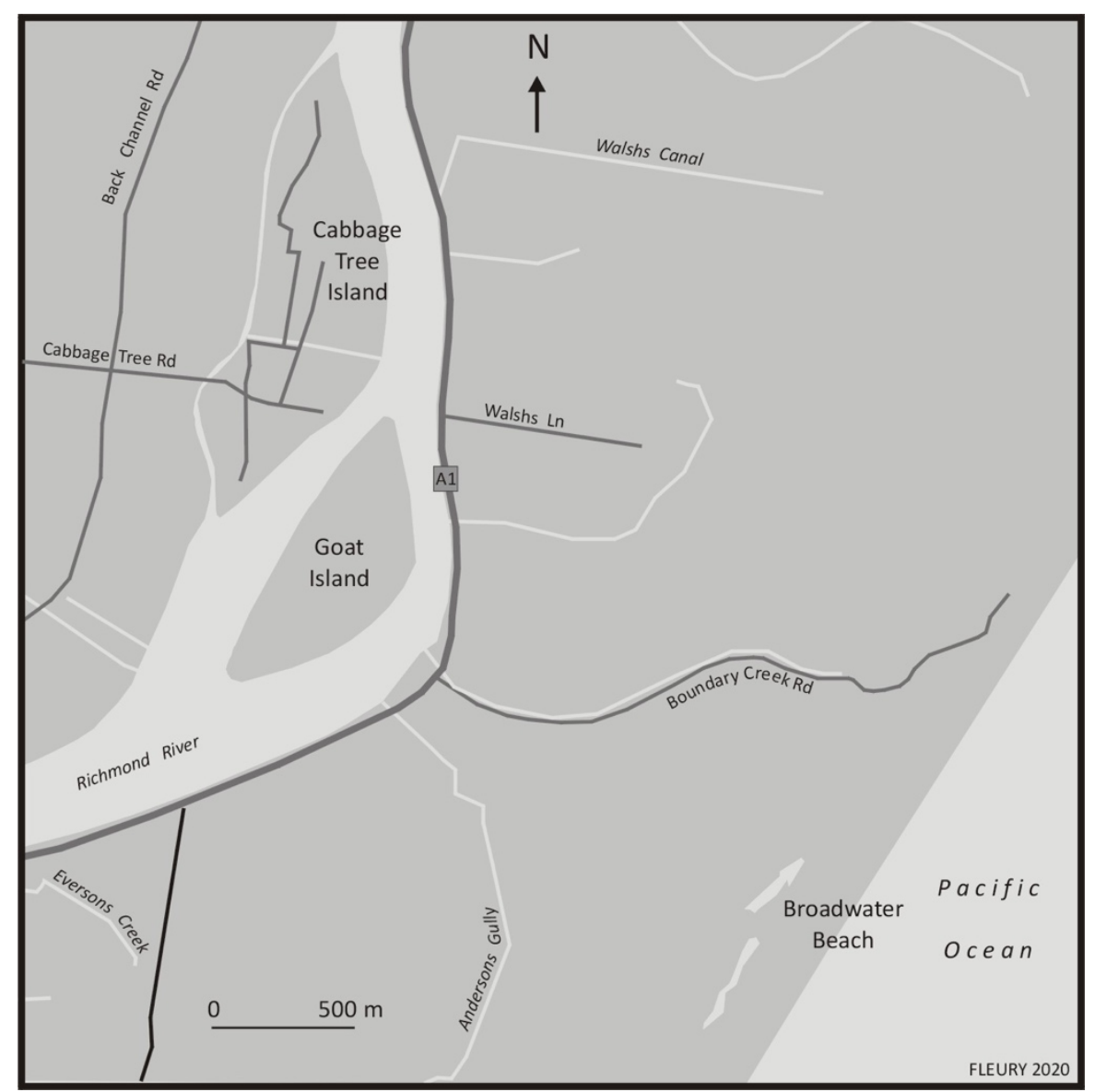

Figure 2: Cabbage Tree Island and other locations within its community's early-mid $20^{\text {th }}$ Century aquapelagic territory. (C) Christian Fleury, 2020

Exemplifying these tendencies, Cabbage Tree Island (Figure 2) first became populated in the 1890s when a group of Bundjalung people living near Lismore decided to seek a locality where they could try and re-establish autonomy and self-sufficiency. To this end, they walked south to the lower Richmond River where they crossed on to a small $\left(0.5 \mathrm{~km}^{2}\right)$ eyot that had become referred to by European settlers as Cabbage Tree Island (after the Cordyline australis tree that grew there). The area had not been claimed or utilised by European settlers, and the new residents cleared areas of the native flora and planted vegetables, fruit trees and sugarcane and established grazing areas for cattle. In combination with fish, shellfish and birds from the river, the island's terrestrial resources proved conducive to the maintenance of a stable population. The presence of the fledgling community was recognised by the NSW Board for the Protection of Aborigines in 1893. Perceived as a suitable place to concentrate local Bundjalung families, the island was gazetted as an Aboriginal 'reserve' (under NSW legislation). This designation allowed the Board to remove Aborigines from the broader community and confine them within areas (in a similar manner to the bantustans established 
in South Africa during the apartheid era; Lissoni \& Ally, 2018). Within the designated Cabbage Tree Island reserve, families from different Bundjalung clans established a collective approach to self-management and inhabited a bounded area that was secure and that they did not have to share with the settler population. This autonomy lasted until 1911 when the Board-bolstered by enhanced powers given to it under the terms of the national Aborigines Protection Act 1909-reclassified the island as a "station." The latter status allowed the Board to appoint a (white) manager to oversee the community, including controlling members' rights to travel off the island. In addition to losing autonomy and having significant aspects of their everyday lives determined by an individual following a national racist agenda, the station manager was allocated an area of land on the island to cultivate their own cattle and crops, significantly restricting the island population's prior self-sufficiency. While precise population statistics are not available, local perceptions suggest that the population peaked at around 200250 in the early 1900s. By the 1920s stresses on the community arising from competing demands on its land area led a number of men to seek paid employment off the island on nearby farms, travelling to the shore on punts. After several generations of what were, by now, islanders, a distinct local culture had become established.

One aspect of the distinct identity referred to above involved a rearticulation of prior patterns of Bundjalung visitation to areas of the Richmond River for food gathering and related ceremonial purposes. This involved the twinning of the bounded space of the island with an area on the opposite shore of the Richmond River around Boundary Creek, a small adjacent lagoon and Broadwater Beach from the 1890s on, effectively creating an expanded aquapelagic space for the community accessed by boat travel across the river and land transit to the lagoon and beach. While access to parts of the eastern shore was complicated by its possession and management by white farmers who had varying degrees of tolerance of Aboriginal visitation to 'their' lands as the $20^{\text {th }}$ century progressed, the significance of the lagoon and shores, and of regular visits to it, have been attested to by a number of Cabbage Tree Island elders (see, for instance, those interviewed in Department of Environment and Climate Change NSW, 2007). Bertha Karpeen's account of visits to the eastern shore in the 1950s and 1960s is also noteworthy:

Well, there used to be a lot of us kids with these older people 'cause they then told us all these stories sort of thing. And we ate [...] 'cause we relied on catching the fish and cooking pipis, that sort of thing $[\ldots]$ in those days, in the early days, there was fish in the lagoon so you could catch fish [...] and so it was a whole day of surviving on what you could catch... [Now] I go with my family and we often sit down and talk about things that I used to [do] and that's knowledge that we pass down. I'll talk about what I used to do when I went out there, and we don't go so much to the lagoon area, but when we get on the beach, I always talk to them about the lagoon and what we did there. Just things we did on the beach, and that's our passing down our culture to the kids. (Planet Corroboree, 2016)

In 1962 a significant change was affected with the construction of a bridge across the narrow western channel of the river, linking the south eastern corner of Cabbage Tree Island to a roadway running north to the towns of Wardell and Ballina. This increased Cabbage Tree Islanders' access to a wider area and to a partial (and still problematic) assimilation and 
participation within the broader population (Burin, 2014; Altman, 1991). These developments led a number of individuals and families to move off the island and resulted in the aquapelagic space encompassing Cabbage Tree Island and the Boundary Creek area to no longer be so actively maintained as it was in the early-mid $20^{\text {th }}$ Century. Despite this, the space and the practices that constituted it, are recognised as an important aspect of community heritage.

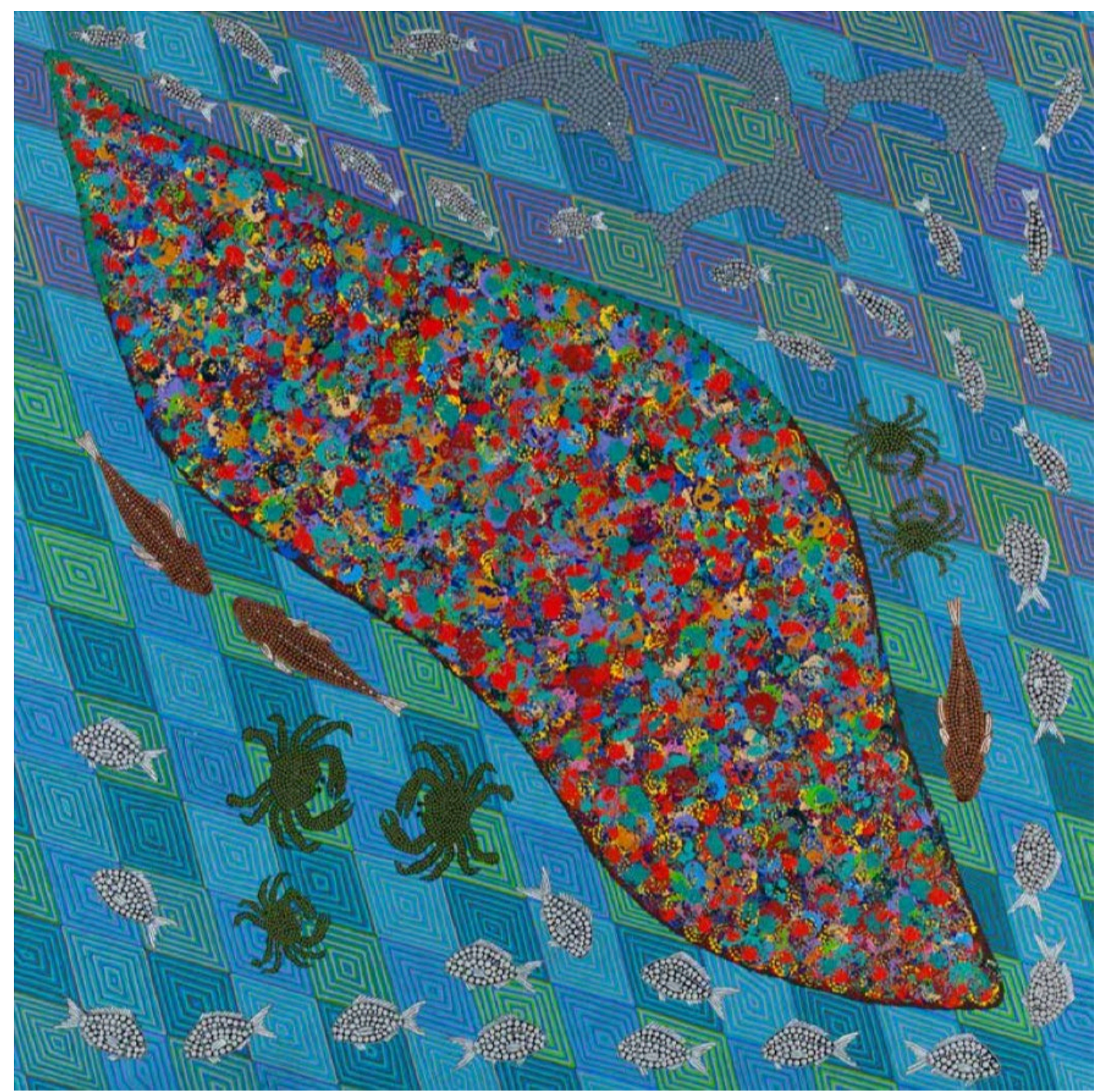

Figure 3: Digby Moran, 'Island Home' (2018).

This heritage has been vividly expressed by artist Albert (Digby) Moran, who was born in Ballina in 1948, to a Bundjalung mother and a Dunghutti father (from the Macleay River region). Moran grew up on Cabbage Tree Island in the 1950s and 1960s and went on to work in the nearby canefields, and then as a prize-fighter, before taking up painting in the 1990s. His artworks reflect his upbringing on the island and his experiences of the Richmond River and its resources. This is exemplified by his painting 'Island Home' (2018) (Figure 3). The painting has a number of notable aspects with regard to perspectives developed in this article. The first concerns the interpretative cartography employed by the artist. While the shape of island corresponds to a conventional cartographic representation, the island's bridge and the east and 
west banks of the Richmond River have been removed. Instead, the island appears located with an area of tidal flats represented by a mesh of diamonds (Pappy, 2017) and with receding rectangular shapes coloured in pale and dark blues and green, representing the dynamic flows and eddies of the river, upon which are superimposed leaping dolphins (emphasising the tidal nature of the lower Richmond), crabs and various types of fish. The island itself is represented with a vivid, intricate patterning of colours in which red and yellow, in particular, serve to emphasise Moran's warm memories of his community on a sliver of land encircled by the river (Frock \& Popart, 2018, p. 10). Presented in this manner-and complemented by the artist's various statements on the topic and related artworks - the aquapelagic orientation of the lifestyle and community experienced by Moran in his youth is vividly realised.

The history mapped above allows us to gain some clarity into a subtle but significant aspect of both socio-geographical concepts of islands and of island studies. This involves two significantly different perceptions of islandness. The first concerns the objective characterisation of islands as bodies of land surrounded by water. The second, closely-but by no means necessarily-associated aspect is the perception that those who live on islands embody an islanded lifestyle, livelihood paths, culture and/or cosmology by dint of their location. The strong, almost 'common-sense,' concatenation of the two lingers in island studies and contributes to the persistence of idealised notions of islands and islandness in some quarters and the flawed nature of analyses and discussions implicitly informed by such perceptions. In partial illustration of this, we can assert that the islandness of Cabbage Tree Island, understood within an island studies perspective, was not generated by the locale's watery border but, rather, coalesced - to the extent that the island effectively came into beingat the moment in which a population became relocated to it and became significantly islanded on it. But, not insignificantly, once established on the tiny island, the community also created and maintained an expanded aquapelagic space between the island, the river, a creek, a lagoon and areas of coastal shoreline.

While it is unclear whether Cabbage Tree Islanders travelled upriver to access it on any occasion, the area around Swan Bay also provided a productive fishing area for Indigenous clans and later European settlers. In contrast to Cabbage Tree Island's strong socio-cultural identity as an island (as evidenced in Moran's previously discussed painting), the encircled area represented in Figure 4 is notable for the manner in which perceptions of its almostislandness primarily result from contemporary cartographic/aerial overviews and a perception of boundedness that can only otherwise be perceived by those residing on or visiting the (now privately owned) area. The area was covered by trees and brush until it was cleared for agricultural usage between the 1870s-1890s, creating a large paddock encircled by a thin fringe of trees, brush and invasive waterside weeds and only broken by the access road running across the north-western isthmus. The fringe of foliage and (moat-like) encircling waters creates a double barrier around the central paddock that renders the encircled terrain as a discrete and highly private space. The hidden status of the almost-island is underlined by the lack of a specific name to refer to it. While the loop is referred to in some cartographical contexts (such as Google Maps) as Serpentine Lagoon, this term is not common in local usage, and the watery loop is most commonly referred to as Swan Bay. The use of the term 'lagoon' to describe an oxbow lake is relatively unusual (being a term commonly used to refer to shallow bodies of coastal water separated from the sea by sandbanks) and, similarly, the term 'bay' more usually refers to coastal or lower estuarine locations. The term Swan Bay also has 
complex and somewhat confusing extended usage, being both the official name for a sparsely populated $2 \mathrm{~km}^{2}$ area to the south of the loop and being a term currently perceived to apply to (but rarely used to refer to) the almost-island (according to local perceptions ascertained through fieldwork and personal communications).

The almost-island results from the partial closure of a loop in the Richmond River due to deposition as part the process that creates the enclosed water formations known as oxbow lakes (Erskine, Melville, Page, \& Mowbray, 1982). The deposition has closed access to the main river at the loop's north-western point, with the north eastern point being connected via a narrow channel. The channel has been subject to intervention in recent years through attempts to arrest the loop's progress to being a shallow, land-locked oxbow lake surrounding a boggy lowland by dredging and deepening the passage to the Richmond River at the loop's northeastern point. Initial work was undertaken in the mid-1950s, primarily to limit flooding of adjacent farmland, and further action was undertaken in 2014 to restore the habitat of the loop by clearing aquatic weeds and increasing water flows, fish stocks and visitations by the black swans (Cygnus atratus) after which the area was named (sometime in the mid-1800s). It is notable, from the perspective of this article, that on the few occasions contemporary media reports have referred to Swan Bay's almost-island, it has either been perceived as farmed paddock almost incidentally located within the loop and/or as an extended bank space along its shores (e.g. Richmond Floodplain News, 2014; Parks, 2014). Like islandness itself, ascription of almost-islandness is a socio-cultural phenomenon that varies in different contexts and is dependent on the nature of human perception and usage of the space concerned.

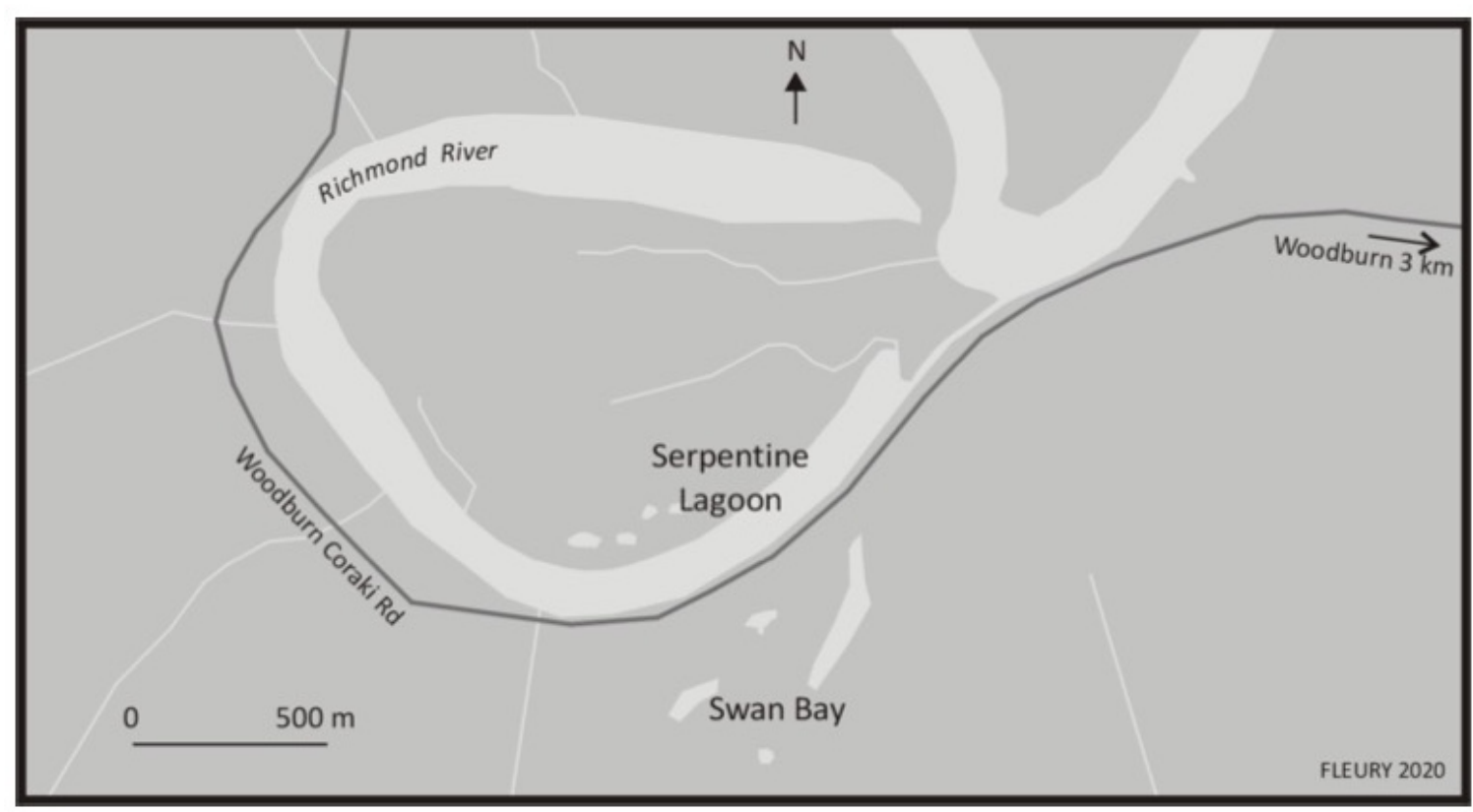

Figure 4: The Serpentine Lagoon/Richmond River loop. (C) Christian Fleury, 2020

\section{Engineered locales on the lower reaches}

While mariners such as James Cook had sailed passed the mouth of the Richmond River during their coastal navigations in the 1770s, it was not until 1828 that it was explored by Europeans when Henry Rous sailed into the estuary and named the river after the English 
Duke of Richmond. Fourteen years later a group prospecting for red cedar trees (Toona ciliata) — which was then one of the world's most valuable woods (Vader, 2002) — travelled north overland from the Clarence River, encountered the Richmond River and identified the north shore of its mouth as suitable for timber processing and port facilities.

The population of the small aggregation of huts that was initially established benefitted from the area's abundant marine food sources, and other settlers subsequently joined the initial party, setting up stores and shipyards. A further stream arrived in the 1860s, following the passing of the NSW Crown Lands Acts in 1861, with several new settlers clearing bush and establishing mixed farm sites to serve the needs of the area's growing population. The planting of sugarcane commenced soon after, with large areas of flatland around the river being acquired by farmer-settlers, establishing a land use pattern that has continued to the present. The arrival of settlers in Bundjalung lands, the development of the Richmond River Heads community and the seizure, clearing and redevelopment of land involved brought the settlers into conflict with local clans, resulting in a series of confrontations. A number of settlers took it upon themselves to respond to these with extreme violence, leading to several massacres of Bundjalung around the northern shore of the estuary in the 1850s (Ainsworth, 1922) and a mass poisoning incident in South Ballina in the early 1860s (Metcalf, 1993). Faced with such violence, clan groups strategically withdrew from the area around the present-day town of Ballina, which went on to develop as a significant commercial centre on NSW's north coast. While there is some dispute over the origins of the name, in that it is closely similar to Buluna, a Bundjalung term for the place where the Richmond River enters the sea and is identical to the name of a town in western Eire, at the mouth of the River Moy, it potentially suggests a co-association of Indigenous and settler heritage terms. Whatever the case, the new name was adopted in the mid-1850s when the settlement was formerly recognised as a town by the NSW government.

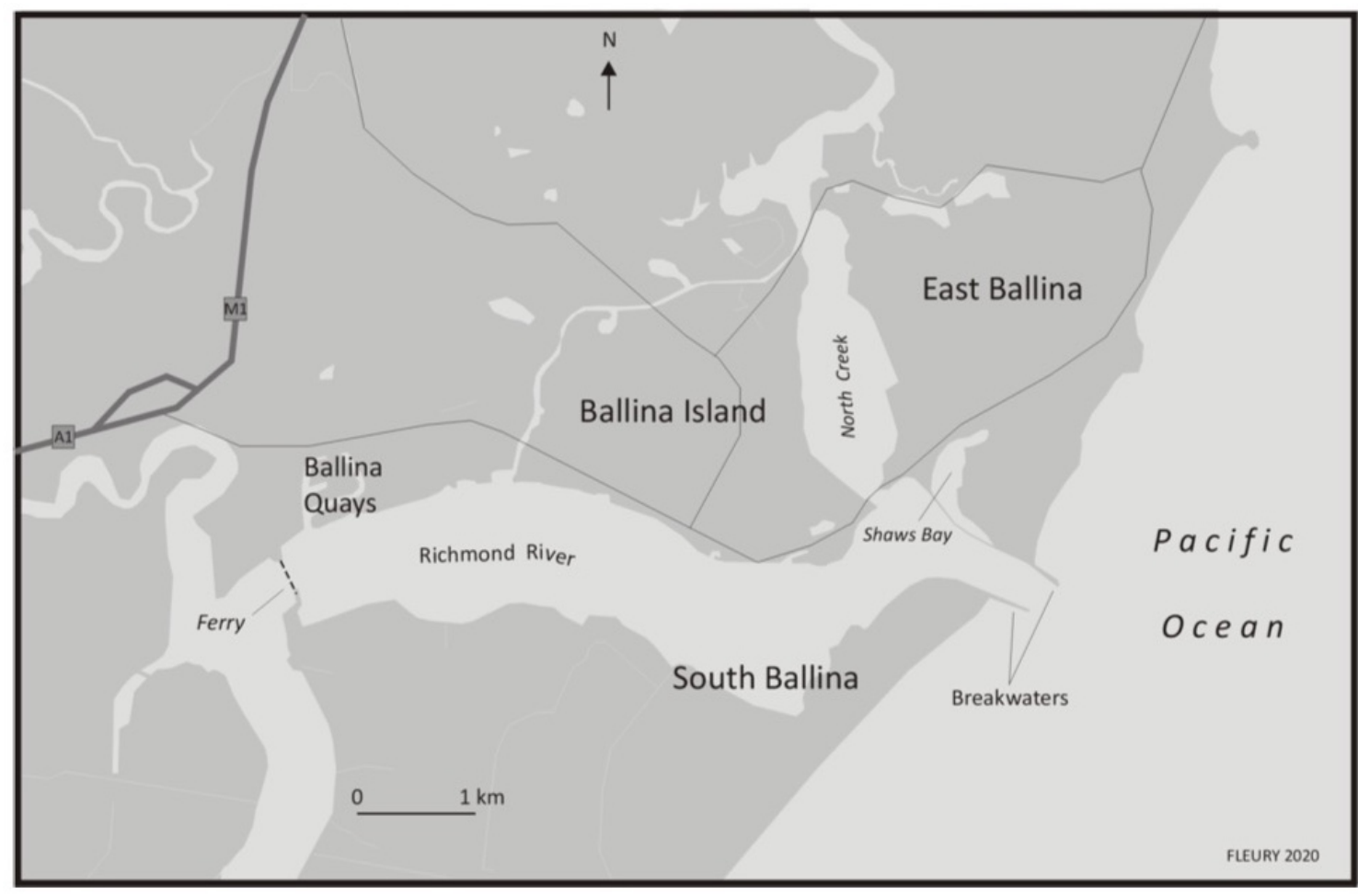

Figure 5: Richmond River at Ballina. (C) Christian Fleury, 2020 
The development of Ballina as a European settler community has involved a series of infrastructural developments. From the earliest stages of settlement, a sandbar at the junction of the river and sea and a series of shifting sandbanks in the two $\mathrm{km}$ stretch of river leading to it provided hazards to navigation, with many ships running aground. As the local cane industry took off in the 1870s and 1880s, these impediments to transport were deemed pressing enough to result in the construction of what are variously referred to as 'training walls' or breakwaters at opposite sides of the heads of the river as it enters the sea (Figure 5). This work was undertaken between 1889-1910 to stabilise the mouth of the river and allow safer access across its sandbar and was initially successful in these regards. Navigation issues in the lower, wide portion of North Creek (Figure 5), which was frequently blocked by silt deposits and shifting sandbanks, were addressed by the construction of a canalised waterway. Using the mouth of Fishery Creek, to the west, as its starting point, the canalised waterway headed north before looping east, cutting a $0.5 \mathrm{~km}$ long channel through marshland to reach North Creek. This not only helped waterflows in North Creek, by providing a second flow into it from the Richmond River, but also provided an easily navigable water route for barges carrying goods to transfer onto sea-going vessels.

Compared to Europe and North America, canals are relatively uncommon in Australia and most of the nine identified and documented by the Australian Canal Society (nd) were short ones constructed in coastal areas in the late- $19^{\text {th }}$ Century to aid the transport of cargo to the sea. While there were precedents in NSW (such as the $200 \mathrm{~m}$ long Shoalhaven canal, constructed in 1822 to address navigation issues at the mouth of the Cookhaven River), the Ballina canal was an ambitious venture for its time. The canal was constructed in 1885-1886, widening and deepening an original creek to a uniform width of 19 metres and minimum (low tide) depth of $2.4 \mathrm{~m}$ and constructing a 500-metre extension through to North Creek. One result of the canalised arc was that the township of Ballina, located to the east of the canal was deprived of a terrestrial access route to its hinterland and was thereby islanded, with the term 'Ballina Island' coming into use to describe the $c 4.5 \mathrm{~km}^{2}$ area around this time. In this manner we can consider the area as having been an almost-island prior to the canalisation and an actual island after. This change was however of relatively little significance since there were no established roads to the township from its hinterland anyway and almost all transport between it and other regional centres, such as Lismore, utilised the river. Similarly, transport to Sydney, the NSW capital, was routinely undertaken by sea.

Ballina stayed fully islanded for 10 years, only being accessible by a ferry across North Creek connecting to a track that led north to a settlement at Lennox Heads before a one-lane timber bridge was built across the Creek, replacing the ferry service. A second bridge was built across the canal on the north coast of the island, connecting to Tamarind Drive, around 1930. A third bridge, linking the island to West Ballina via River Street, was added around 1956, and a fourth, across the upper part of North Creek, was completed in 1996. The introduction of bridges to the island reflected both the development of adjacent areas on the north shore of the Richmond River and the construction of the major coastal road route between Sydney and Brisbane. The latter was completed 1909, albeit with many stages, particularly in northern NSW, being dirt tracks and with many of the larger rivers it encountered requiring ferry crossings. Sealing of the entire route of (what became known as) the Pacific Highway was completed in 1958 and the last ferry routes (across the Richmond and Clarence Rivers) were superseded by bridges in 1964 and 1966, respectively. These 
important infrastructural developments led to the consolidation of Ballina as a local government area that now has a population of 44,628 (Ballina Shire Council, 2019a). While the town was established as a port and transit area, it is now largely residential, with healthcare and social assistance being the largest employment sector (16\%), reflecting the large number of retirees, retirement estates and age-care facilities in the area, and with retail (11.6\%) and education and training (11.1\%) as the next largest sectors (Ballina Shire Council, 2019b).

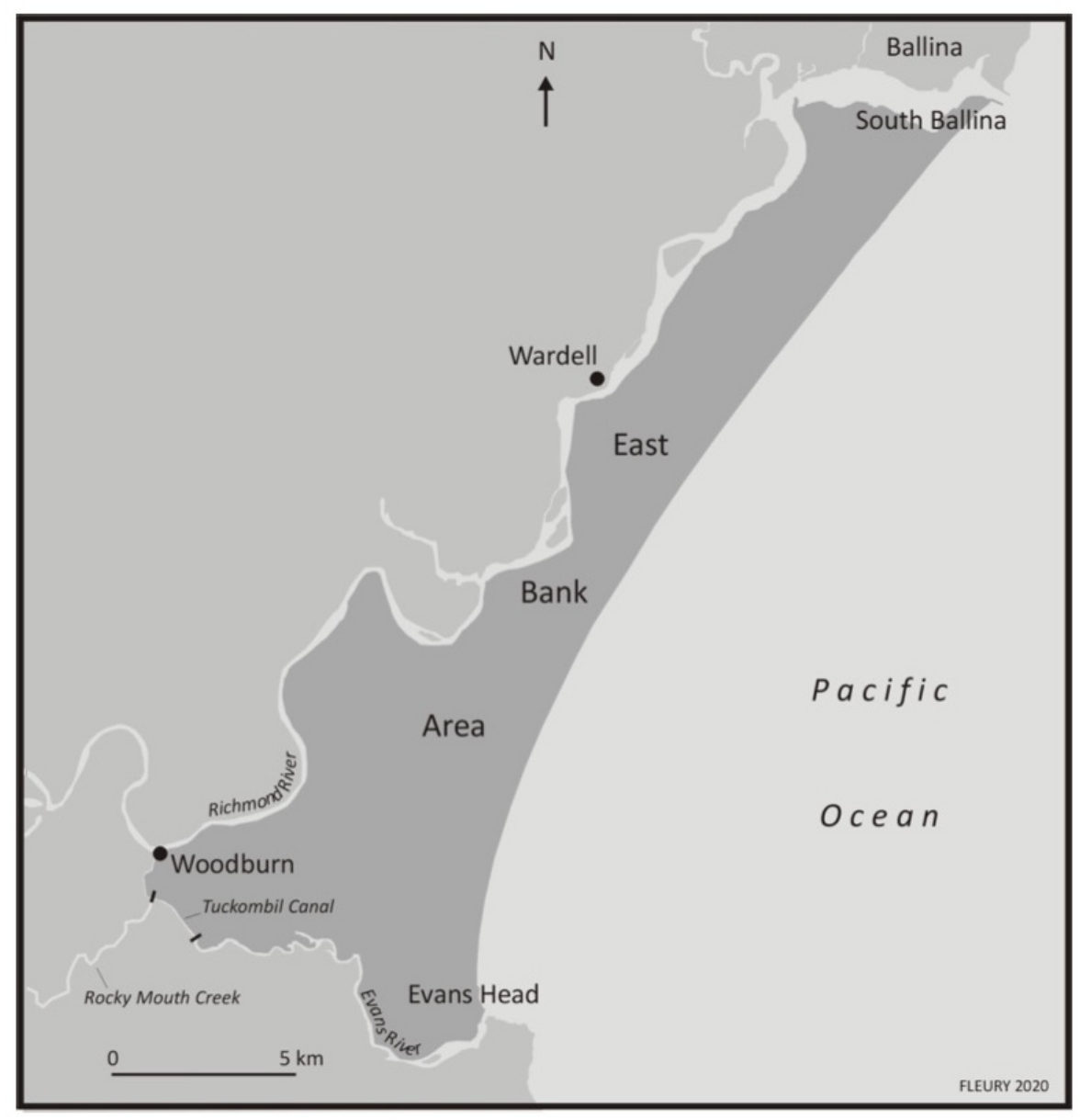

Figure 6: East Bank Area. (C) Christian Fleury, 2020

The decline of water-based transport and the spread of roadways and bridges also modified spaces adjacent to the Richmond River. This is particularly evident in the case of South Ballina, the end point of a long, thin, low-lying body of land, measuring $33 \mathrm{~km}$ from south-west to north-east, bounded by the Richmond River on its western wide and by the Pacific Ocean on its eastern side (Figure 6). During Ballina Island's heyday as a port on an estuary where water transport was key, South Ballina was as effectively islanded and connected to nearby and remote locales as Ballina Island itself. In this context, it was also of little significance that South Ballina was at the northern end of a peninsula linked to the coast to its south by a narrow land connection between Rocky Mouth Creek and Evans River, as this was not used by settlers as a north-south access route. Referring to the above as East Bank Area (EBA) for the purposes of this discussion, it is notable that, until the mid-20th Century, EBA was an almost-island. It became fully islanded in the early 1960s, when a short, engineered waterway (known as Tuckombil Canal) was constructed across the southern land 
neck to link the Richmond and Evans Rivers and to provide enhanced drainage for lowlying land around Swan Bay/Serpentine Creek and adjacent areas. Indeed, it was of greater significance for the population of the lower EBA, and for non-residents travelling along the developing road links between Sydney and Brisbane, that the construction of bridges between the EBA and the adjacent 'mainland' at various points (across the Evans River at Evans Head, across Tuckombil Canal and across the Richmond River at Woodburn, Broadwater and Wardell) in the early to mid-20 ${ }^{\text {th }}$ Century increased the area's integration with areas to its south and lower-mid western reaches.

In its initial phase, the Pacific Highway crossed on to EBA over Tuckombil Canal, just south of Woodburn, and then followed the east bank of the Richmond River up to South Ballina. Dual ferries then took vehicles across the narrow neck in the river from Burns Point to West Ballina, where the highway recommenced, running to the west of Ballina Island and on north to Mullumbimby. While workable, this route was far from desirable, resulting in major queues around the Burns Point ferry at busy times of the year. This transit bottleneck was remedied by the opening of a bridge across the Richmond River at Wardell in 1964, which allowed the Pacific Highway to follow a quicker route to Ballina, cutting across to the western side of the river. As a result of this development, the stretch of road on EBA north of Wardell Bridge immediately lost the vast majority of its traffic, and the regular free ferry service at Burns Point was replaced by a downgraded one that charged a fee and ran less frequently. The new, diminished ferry operation served the small communities on the east bank of the river, allowing them access to Ballina's facilities, and allowed easy reverse access over from Ballina for recreational and tourist purposes. In this manner, the diversion of the Pacific Highway served to re-instate a significant degree of isolation/islanding for South Ballina and the adjacent communities of Keith Hall and Empire Vale. The complexities of spatial politics arising from this are still manifest in local perceptions of transport access and infrastructure. In response to Ballina Council's hike in ferry fees in 2009, for instance, local resident Loraine Leuckel claimed that the ferry "should be looked on as an extension of the road because this [i.e. South Ballina] is the mainland and Ballina is the island" (Ballina Advocate, 2009).

The islandishness of Ballina Island-both as an area within greater Ballina and as a central area emblematic of the broader town-is infrequently mobilised in official discourse. One notable exception to this is local historian Cliff Murray's centennial history of Ballina shire. The book's title, Across three bridges: Island base for council 1883-1983, identifies Ballina Island as the epicentre of the community and emphasises the (then) three bridges that linked the island to adjacent 'mainland' areas. Despite the clear statement of place identity - and of Ballina Island as the geo-spatial centre and base of the shire- on its cover (Figure 7), the council-funded book otherwise largely bypasses such an orientation in its detailed account of local politics, politicians and public works developments. 


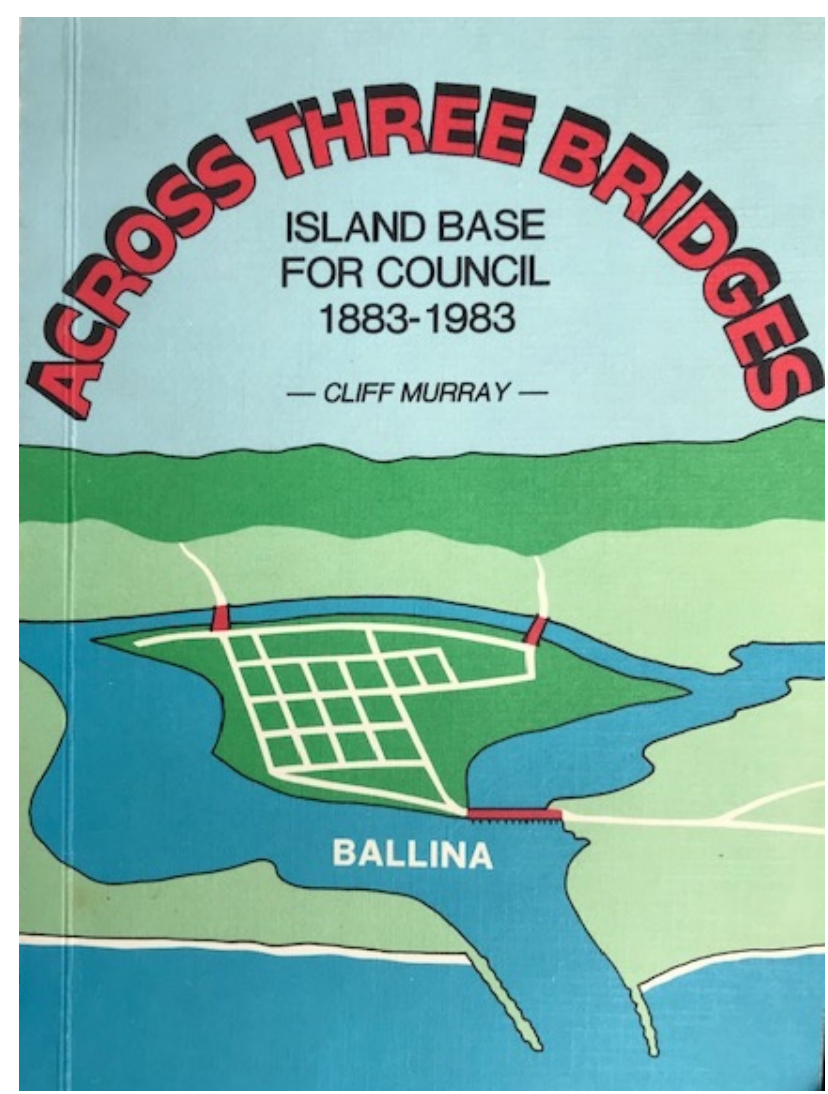

Figure 7: Front cover of Cliff Murray's book Across Three Bridges (1983).

While the cover of Murray's book may make the matter plain (at least, for the limited audience who were keen enough about council history to access it), the location of an island in Ballina is the subject of some confusion amongst newly arrived residents and/or visitors. Sustained anecdotal research suggests that, in contrast to Leuckel's observation, a significant number of new residents and tourists perceive South Ballina to be Ballina Island, largely on account of its access by ferry from Ballina and the lack of any signage indicating a road route between Ballina and South Ballina. Confusion on the west bank of the river has also been compounded by establishments such as a motel located on River Street (500 $\mathrm{m}$ to the east of the Fishery Creek canal and thereby not on the island) operating as the Ballina Island Motor Inn in the 1990s-2000s before more recently changing its name to the (more ambiguous and somewhat geographically scrambled) Ballina Byron Islander Resort.

On those occasions when Ballina Island's islandness is mobilised, it is often understood and communicated within the context of a bridged island within a marine resource zone. Promotional flyers for the 2015 Prawn Festival, held in Missingham Park, for example, (correctly) stated the event's location as being on Ballina Island but accompanied its text with a photo of a coastal location (Cabral, 2015). More recently, local artist Rachel Stone collaborated with students from Ballina Public School to produce six banners with aquatic themes that were hung from the bridges across the canal and nearby posts, marking the boundaries of the island with aquatic symbols. In a statement accompanying their installation, Stone identified that "Ballina is an island surrounded by water, so bridges are pretty important here" (Ballina Coast and Hinterland, 2016). Along with Stone's artwork and the aforementioned festival, the popular roadside attraction known as the 'Big Prawn' (outside Bunnings DYI centre in West Ballina) commemorates the manner in which Ballina has 
sustained a fishing fleet from its harbour at the junction of Richmond River and North Creek Canal that has brought the area a reputation for the quality of its prawns, thereby enhancing the area's association with coastal waters.

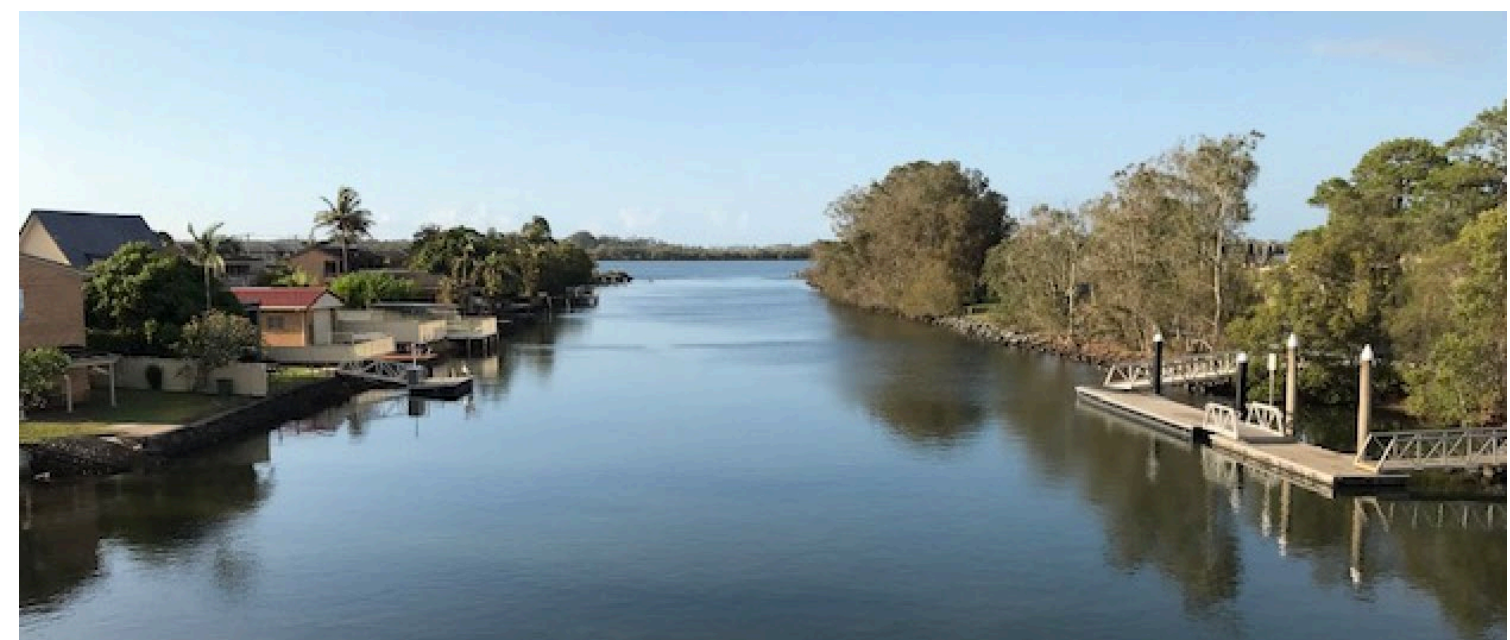

Figure 8: Initial stretch of North Creek canal, showing its connection to the Richmond River, looking south from River Street Bridge. (C) Philip Hayward, 2019

Along with the canal's islandising effects and its impact on boosting commercial efficiency in the late 1800 s, its principal contemporary significance has been the creation of a quiet, corridor interrupting the sprawl of the inner township of Ballina out into East Ballina (Figure 8). The corridor comprises the canal itself, which rarely carries anything other than small leisure craft, and an elongated public reserve comprising a mown grass area dotted with native trees, along its eastern bank, before it turns east to enter North Creek. The reserve also features remnant heritage structures that mark the area's status as an engineered landscape.

Two other significant modifications to Ballina's waterfrontage and associated residential and leisure amenities have resulted from very different types of engineering. The first is the previously discussed construction of breakwaters, stabilising the river's entry to the sea, which has both had effects on the erosion and deposition of ocean front beaches in the vicinity (Haijun et al, 1999) and created a distinct new coastal space at Shaws Bay, on the north bank. The erection of a sea wall at Shaws Bay turned a tidal bay into a semi-enclosed embayment with restricted tidal flushing, creating a calm water space good for fishing and swimming but also prone to pollution from stormwater run-offs that feed directly into it (Ballina Shire Council, 2000). Aside from its impact on Shaws Bay, the path constructed along the top of the seawall from the north-west corner of the bay out to the end of the wall at the heads has become a much-used walking track, allowing pedestrians scenic views across the estuary and of the dolphins and seabirds that frequent the area. By contrast, the second significant engineering development occurred in West Ballina, immediately to the east of the Burns Point ferry. This comprises Ballina Quays, a small-scale FICE similar to those constructed $110 \mathrm{~km}$ north at the Gold Coast. As we have previously emphasised (Hayward \& Fleury, 2016), FICEs are specifically designed to create private waterfront spaces for residents and, with their preponderance of cul-de-sacs, lack of public foreshore spaces and usually singular access points to nearby main roads, are uninviting and uninteresting places for outsiders to visit. This characterisation is apt for Ballina Quays, which is effectively a private waterfront enclave that 
is 'islanded' within/from the broader region by virtue of its privately owned, limited-access waterfront areas.

\section{Conclusion}

Our discussion of the complex geo-physical and social aspects of the lower Richmond River brings island studies' perspectives to bear on what is, for the interdisciplinary field as it has developed to date, an atypical object of study. This atypicality has required us to adopt an "expanded" island studies approach that addresses issues of bridging, peninsular almostislandness and riverine transport as key elements in the socio-geography we explore.

Our study of Indigenous and European settler perceptions and usages details how the islands of the region are best understood as elements of an integrated riverine/terrestrial assemblage rather than as isolates within that space. In an environment such as the lower Richmond River, which has seen major structural modifications around its entrance to the sea and the construction of a series of bridges, isolation and connectivity have been actively negotiated and reconstituted through both local level initiatives and broader regional schemes. While Indigenous communities have been decimated, and their remnants relocated and reconstituted in fresh cultural and spatial contexts, they have continued to have a significant presence within the novel socio-economic and material spaces settlers have created in the region. Over the last 130 years, flux has been ever present around the lower Richmond River, and the islands and shorelines have been physically and socio-culturally reconstituted in a serial manner. Just as fluvial processes have produced river islands that humans have utilised and modified in various ways, flows of raw materials and populations through the area have deposited particular structures, institutions, practices and perceptions around it.

If the archetypal saltwater islands considered by island studies (such as Tierra de Fuego, Tresco or Tristan da Cunha, to name but three) may be considered as solid, fixed and unambiguous, riverine ones, such as those considered in this article, are decidedly not. Our research suggests that, in some locations, at least, islandness - and the islanding and deislanding of areas - might best be considered as processual and, thereby as temporally variable. This is perhaps the most salient point island studies might take from our discussions. The islandness of islands can be profitably reconceptualised in a manner that is more fluid and flexible, less premised on particular paradigms of rugged, resilient materiality and more open to inclusivity, to a spectrum of identities. As Hong's (2020) study of Chinese river islands also concluded, such an orientation would recognise, allow, and encourage explorations of geo-physical and socio-cultural perceptions of islandness that acknowledge how these are interwoven in uneven manners and are far from fixed or uniform. Equally, in such contexts, islandness, almost-islandness and/or aquapelagality may be understood as points along a spectrum of possibilities enacted at particular periods rather than as discrete fixities.

\section{Acknowledgements}

Thanks to the Muurrbay Aboriginal Language and Culture Co-op, Richmond River Historical Society, Rob Garbutt, Grayson Cooke, Patrick Knight, Kerry Moran, Amanda Reichelt-Brushett, Adele Wessell and Michael Wood for various research assistances. 


\section{References}

Ainsworth, J. (1922, October 14). An East Ballina massacre: Shot down like dogs. The Don Dorrigo Gazette and Guy Fawkes Advocate, 4.

Altman, J.C. (Ed.). (1991). Aboriginal employment equity by the year 2000. Center for Aboriginal Policy Research, Australian National University.

Anderson, R. (2016). Islands within an almost island: Baja California. Shima 10(1), 33-47.

Australian Canal Society (nd). Australian canals. Retrieved from http://www.auscanal.org.au/Auscan.html

Baldacchino, G. (Ed.) (2007). Bridging islands: The impact of fixed links. Acorn Press.

Ballina Advocate (2009, May 14). Fuming over ferry fee. Retrieved from https://www.ballinaadvocate.com.au/news/fuming-over-ferry-fee/227243/

Ballina Coast and Hinterland (2020). Canal and Fishery Creek bridge banners. Retrieved from https://www.discoverballina.com.au/visit/placemaking-flags-banners-andpublic-art/489-bridgesbanner

Ballina Shire Council (2004). Wardell community-based heritage study. Retrieved from https://ballina.nsw.gov.au/files/Wardell Community Based Heritage Study.pdf

Ballina Shire Council. (2019a). Estimated resident population. Retrieved from https://profile.id.com.au/ballina/population-estimate

Ballina Shire Council (2019b). Industry sector of employment. Retrieved from https://profile.id.com.au/ballina/industries

Ballina Visitor Information Centre (2020). Discover Ballina. Retrieved from https://www.discoverballina.com.au/visit/our-region/towns-villages/ballina

Baruah, M.,\& Mukherjee, J. (2018). Rivers and Estuaries. In G. Baldacchino (Ed.), The Routledge international handbook of island studies (pp. 324-338). Taylor \& Francis. https://doi.org/10.4324/9781315556642-15

Bundjalung-Yugambeh Dictionary (2020). Retrieved from http://bundjalung.dalang.com.au/plugin wiki/index.html

Burin, M. (2014). Cabbage Tree Island and the vision for a self-sufficient Aboriginal community. Retrieved from https://www.abc.net.au/local/videos/2014/10/28/4116463.htm

Carbrall, H. (2015) Ballina Prawn Festival. Retrieved from https://www.youtube.com/watch?v=inK56uDBkic

Casagrande, M. (2016). Heritage, tourism, and demography in the island city of Venice: depopulation and heritagisation. Urban Island Studies, 2, 121-141. https://doi.org/10.20958/uis.2016.6

Department of Environment and Climate Change NSW. (2007). Aboriginal women's heritage: Ballina and Cabbage Tree Island. Retrieved from https://www.environment.nsw.gov.au/resources/cultureheritage/07464BallinaCabba geTree.pdf

Erskine, W., Melville, M., Page, K.J., \& Mowbray, P.D. (1982). Cutoff and oxbow lake. Australian Geographer, 15(3), 174-180. https://doi.org/10.1080/00049188208702813

Fleury, C., \& Raoulx, B. (2016). Toponymy, taxonomy and place: explicating the French concepts of presqu'île and péninsule'. Shima, 10(1), 8-20.

https://doi.org/10.21463/shima.10.1.04 
Frock, E., \& Popart, P. (2018). Growing up on the island (catalogue). Lismore Regional Gallery. Retrieved from https://issuu.com/lismoreregionalgallery/docs/lrg digby moran catalogue issuu

Gold, A. (2016). Gibraltar - a paradigmatic presqu'ile? Shima 10(1), 21-32.

Grydehøj, A. (2017). A future of island studies. Island Studies Journal, 12(1), 3-16. https://doi.org/10.24043/isj.1

Grydehøj, A. (2015). Making ground, losing space: land reclamation and urban public space in island cities. Urban Island Studies, 1, 96-116.

https://doi.org/10.20958/uis.2015.6

Grydehøj, A., \& Casagrande, M. (2020). Islands of connectivity: archipelago relationality and transport. Area 52(1), 56-64. https://doi.org/10.1111/area.12529

Gupta, P. (2015). Futures, fakes and discourses of the gigantic and miniature in 'The World' islands, Dubai. Island Studies Journal 10(2), 181-196.

Hai-jun, H., Short, A.D., Zeng, T., \& Hanslow, D. (1999). Impact of river training walls on adjacent beaches, Ballina, New South Wales, Australia. Chinese Journal of Oceanology and Limnology, 17, 41-48. https://doi.org/10.1007/bf02842698

Hayward, P. (2014). Towards an expanded version of island studies. Shima 10(1), 2-7.

Hay, P. (2013). What the sea portends: a reconsideration of contested island tropes. Island Studies Journal, 8(2), 209-232.

Hideshi, U. (2013, June 10). The problems in the South China Sea. Review of Island Studies. Retrieved from http://islandstudies.oprf-info.org/research/b00004/

Hong, G. (2020). The place-specific geographies of inhabited river islands on the ruralurban fringe of inland China: A critical-holistic approach. Shima, 14(2), 81-98. https://doi.org/10.21463/shima.14.2.11

Kijas, J. (2019). An echo of wings: The history of the Tuckean Swamp. Retrieved from https://ozfish.org.au/wp-content/uploads/2019/11/FINAL-An-Echo-of-Wings-zzA-History-of-the-Tuckean-Swamp-June-2019.pdf

Lahiri-Dutt, K., \& Gopa. S. (2014). Dancing with the river: People and life on the chars of South Asia. Yale University Press. https://doi.org/10.1080/00856401.2014.890504

Lahiri-Dutt, K. (2014). Chars: Islands that float within rivers. Shima, 8(2), 22-38.

Larkin, B. (2013). The politics and poetics of infrastructure. Annual Review of Anthropology 42, 327-343.

Lissoni, A., \& Ally, S. (2019). Bantustan states. African Historical Review, 50(1-2), 1-3. https://doi.org/10.1080/17532523.2019.1596405

Metcalf, R. (1993, April 7). Flour laced with arsenic brings on mass poisoning. Koori Mail.

Murray, C. (1983). Across three bridges: Island base for council 1883-1983. Ballina Shire Council.

Pappy, L. (2019). Diamonds by Digby Moran, Lismore City Hall, NSW, Australia. Retrieved from https://www.youtube.com/watch?v=ivfNfMJrTqQ

Parks, A. (2014, August 27). Swans return to Swan Bay after habitat restoration work. Northern Star. Retrieved from https://www.northernstar.com.au/news/swans-showsuccess/2365157/

Planet Corroboree (2016). Cabbage Tree Island. Retrieved from https://planetcorroboree.com.au/blogs/culture-country/cabbage-tree-island 
Potiki, M. (2016). The Otago peninsula: A unique identity. Shima 10(1), 67-84.

Richmond Floodplain News (2014). Swans return to Swan Bay. Richmond Floodplain News.

Ryan, J.S. (1963). Some Aboriginal place-names in the Richmond Tweed area. Oceania, 34(1), 38-55. https://doi.org/10.1002/j.1834-4461.1963.tb00247.x

Sharpe, M.C. (1985). Bundjalung settlement and migration. Aboriginal History, 9(1), 101-124.

Timothy, D. (2018). Foreword. In Vallerani, F. \& Visentin, F. (Eds), Waterways and the cultural landscape (pp. xviii-xx). Routledge.

Vader, J. (2002). Red gold: The tree that built a nation. New Holland.

Vallerani, F. (2018). Introduction: Flowing consciousness and the becoming of waterscapes. In F. Vallerani \& F. Visentin (Eds.), Waterways and the cultural landscape (pp. 1-16). Routledge. https://doi.org/10.4324/9781315398464

Visentin, F. (2018). Conclusion: Towards a humanistic hydrology. In F. Vallerani \& F. Visentin (Eds.), Waterways and the cultural landscape (pp. 266-259). Routledge. https://doi.org/10.4324/9781315398464

Walford, E. (1878). Old and new London: Volume 5. Cassell, Petter \& Galpin.

Zhang, H., \& Grydehøj, A. (2020). Locating the interstitial island: Integration of Zhoushan Archipelago into the Yangtze River Delta urban agglomeration. Urban Studies. https://doi.org/10.1177/0042098020937987 